\title{
The trans-subclavian retrograde approach for transcatheter aortic valve replacement: Single-center experience
}

\author{
Giuseppe Bruschi, MD, ${ }^{\mathrm{a}}$ Pasquale Fratto, MD, ${ }^{\mathrm{a}}$ Federico De Marco, MD, ${ }^{\mathrm{a}}$ Jacopo Oreglia, MD, ${ }^{\mathrm{a}}$ \\ Paola Colombo, MD, PhD, ${ }^{\mathrm{a}}$ Luca Botta, MD, ${ }^{\mathrm{a}}$ Aldo Cannata, MD, ${ }^{\mathrm{a}}$ Antonella Moreo, MD, ${ }^{\mathrm{a}}$ Benedetta De \\ Chiara, MD, ${ }^{\mathrm{a}}$ Francesca Lullo, MD, ${ }^{\mathrm{b}}$ Roberto Paino, $\mathrm{MD},{ }^{\mathrm{b}}$ Luigi Martinelli, $\mathrm{MD},{ }^{\mathrm{a}}$ and \\ Silvio Klugmann, $\mathrm{MD}^{\mathrm{a}}$
}

Objective: Aortic valve disease is the most common acquired valvular heart disease in adults. With the increasing
elderly population, the proportion of patients with symptomatic aortic stenosis who are unsuitable for conven-
tional surgery is increasing. Transcatheter aortic valve implantation has rapidly gained credibility as a valuable
alternative to surgery to treat these patients; however, they often have severe iliac-femoral arteriopathy, which
renders the transfemoral approach unusable. We report our experience with the trans-subclavian approach for
transcatheter aortic valve implantation using the CoreValve (Medtronic CV Luxembourg S.a.r.l.) in 6 patients.

Methods: In May 2008 to September 2009, 6 patients (mean age of $82 \pm 5$ years), with symptomatic aortic stenosis and no reasonable surgical option because of excessive risk, were excluded from percutaneous femoral CoreValve implantation because of iliac-femoral arteriopathy. These patients underwent transcatheter aortic valve implantation via the axillary artery. Procedures were performed by a combined team of cardiologists, cardiac surgeons, and anesthetists in the catheterization laboratory. The CoreValve $18 \mathrm{~F}$ delivery system was introduced via the left subclavian artery in 6 patients, 1 with a patent left internal thoracic to left anterior descending artery graft.

Results: Procedural success was obtained in all patients, and the mean aortic gradient decreased $5 \mathrm{~mm} \mathrm{Hg}$ or less immediately after valve deployment. One patient required implantation of a permanent pacemaker. One patient required a subclavian covered stent implantation to treat a postimplant artery dissection associated with difficult surgical hemostasis. One patient was discharged in good condition but died of pneumonia 40 days after the procedure. All patients were asymptomatic on discharge, with good mid-term prosthesis performance.

Conclusions: Transcatheter aortic valve implantation via a surgical subclavian approach seems safe and feasible, offering a new option to treat select, inoperable, and high-risk patients with severe aortic stenosis and peripheral vasculopathy. (J Thorac Cardiovasc Surg 2010;140:911-5)

\section{Supplemental material is available online.}

Aortic stenosis (AS) is the most frequent form of valvular heart disease in adults in western countries, ${ }^{1}$ and aortic valve replacement is the standard treatment for these patients. ${ }^{2}$ However, the mortality rate associated with aortic valve replacement increases substantially with age, the presence of left ventricular dysfunction, or multiple comorbidities. ${ }^{3}$ In recent years, transfemoral ${ }^{4,5}$ or transapical ${ }^{6}$ transcatheter aortic

\footnotetext{
From the A De Gasperis Cardiology and Cardiac Surgery Department, ${ }^{\text {a }}$ and Cardiothoracic Anesthesia and Intensive-care, ${ }^{\mathrm{b}}$ Niguarda $\mathrm{Ca}$ ' Granda Hospital, Milan, Italy. Disclosures: None.

Received for publication Nov 13, 2009; revisions received Dec 28, 2009; accepted for publication Jan 22, 2010.

Address for reprints: Giuseppe Bruschi, MD, A De Gasperis Cardiology and Cardiac Surgery Department, Niguarda Ca' Granda Hospital, Piazza dell'Ospedale Maggiore 3, 20162 Milan, Italy (E-mail: giuseppe.bruschi@fastwebnet.it). $0022-5223 / \$ 36.00$

Copyright (c) 2010 by The American Association for Thoracic Surgery doi:10.1016/j.jtcvs.2010.01.027
}

valve implantation (TAVI) has rapidly gained credibility as a valuable alternative to treat this group of patients who are not considered for surgery because of significant comorbidities. $^{7,8}$ The 2 devices currently clinically available are the Edwards-Sapien stainless-steel, balloon-expandable bovine bioprosthesis (Edwards Lifesciences, Irvine, Calif) and the CoreValve nitinol porcine self-expanding bioprosthesis (Medtronic CV Luxembourg S.a.r.l.). The transfemoral approach is the preferred method for both devices, but with a $24 \mathrm{~F}$ or $18 \mathrm{~F}$ introducer, respectively, the presence of small, tortuous, heavily calcified femoral and iliac arteries contraindicates this approach. To prevent vascular complications in this group of patients, a transapical approach with the Ascendra transapical catheter and the Edwards-Sapien valve (Edwards Lifesciences) was preferred, but there is only experimental experience with this approach using the CoreValve. This approach seems demanding because it requires direct left ventricle apex surgical exposure and a dedicated operating room. We report our experience with retrograde CoreValve implantation through the axillary artery in 6 high-risk surgical candidates with severe AS and heavily calcified and atherosclerotic femoral and iliac arteries. 


\section{Abbreviations and Acronyms \\ AS $=$ aortic stenosis \\ TAVI $=$ transcatheter aortic valve implantation}

\section{MATERIALS AND METHODS}

From May 2008 to September 2009, 120 patients with severe, symptomatic AS and no reasonable surgical option because of excessive risk were evaluated for TAVI. The patient screening protocol included transthoracic echocardiography, complete left-sided heart catheterization, and coronary angiography, with angiography of the iliac and femoral arteries, and chest and aortic-iliac-femoral computed tomography scans. Acceptance for the procedure required consensus by a team composed of a cardiac surgeon, an interventional cardiologist, the referring cardiologist, and a cardiac anesthesiologist. All patients provide written informed consent, and all procedures were approved by the local ethics committee. Forty-five patients were eligible for CoreValve percutaneous femoral implantation, whereas 6 patients ( 5 male) with a mean age of $82 \pm 5$ years were excluded because of small size, calcification, iliac-femoral arteriopathy, or excessive tortuosity. These patients underwent CoreValve implantation via the left axillary artery. All patients underwent supra-aortic vessel angiography and computed tomography to assess the left subclavian artery size, course, and calcification (Figure E1). Two patients had previously undergone coronary artery bypass grafting, and 1 patient had a patent left internal thoracic to left anterior descending artery graft. Two patients had severe left ventricular dysfunction, and 3 patients underwent a bridge procedure of balloon aortic valvuloplasty. The patients' characteristics are shown in Table 1.

The CoreValve ReValving System consists of 3 unique components: a self-expanding support frame with a trileaflet porcine pericardial tissue valve, an $18 \mathrm{~F}$ catheter delivery system, and a disposable loading system, as previously described. ${ }^{9-11}$

\section{Operative Technique}

The procedure was performed in the cardiac catheterization laboratory by a team of interventional cardiologists, cardiac surgeons, and a cardiac anesthesiologist. All procedures were performed under general anesthesia. The best femoral artery was accessed by a single wall puncture under fluoroscopic and angiographic guidance to allow homodynamic monitoring and landmark aortic angiography through a $5 \mathrm{~F}$ pigtail. A temporary pacing lead was advanced in the right ventricle through the right femoral vein in the patients without a permanent pacemaker to treat possible post-TAVI atrioventricular block. Heparin was administered to maintain an activated clotting time greater than 250 seconds throughout the procedure. The axillary artery was surgically isolated through a subclavicular incision of 3 to $5 \mathrm{~cm}$ just below the clavicle (Figure E2). Arterial cannulation was performed using the Seldinger technique through a purse-string suture. The left axillary artery was usually preferred because of the best angle of deployment. A 7F sheath was then inserted into the subclavian artery, and a 0.035 straight guidewire was placed in the left ventricle using a left Amplatz catheter (Amplatz Cook, Inc, Bloomington, Ind). A Cook 30-cm Check-Flo Performer 18F introducer (William Cook Europe, Bjaeverskov, Denmark) was inserted (Figure 1) over an Amplatz super stiff guidewire, and the native aortic valve was predilated with a 22or 25-mm Nucleus balloon (NuMED Inc, Hopkinton, NY) without rapid pacing in all patients. The balloon design facilitates positive positioning while holding the balloon in the correct location, and initial inflation will hold the balloon in the desired position. A CoreValve prosthesis was then carefully introduced and retrogradely implanted under angiographic and fluoroscopic guidance over the stiff wire in the ascending aorta across the aortic valve (Figures 2, E3, and E4) with immediate improvement of the hemodynamic status in all patients. Immediately after CoreValve deployment, ascending aorta angiography was performed to assess the patency of the coronary arteries and coronary grafts, and the presence and location of the eventual paravalvular leak (Figure 3). After the procedure, heparin was neutralized by protamine, and the subclavian artery was restored by direct suture.

\section{Statistical Analysis}

Incidence rates of events are reported by giving the number of patients experiencing the event followed by the corresponding percentage. Continuous data are reported by giving the mean \pm standard deviation or median and the range of values observed.

\section{RESULTS}

According to definitions by Piazza and colleagues, ${ }^{12}$ procedural success was defined by the combination of 3 different end points: adequate technical placement, normal bioprosthesis performance, and operative outcome. Adequate technical placement was the correct positioning of the

TABLE 1. Baseline patient characteristics at implant

\begin{tabular}{|c|c|c|c|c|c|c|c|c|c|c|c|}
\hline \multirow[b]{2}{*}{ Patient } & \multirow[b]{2}{*}{ Gender } & \multirow{2}{*}{$\begin{array}{l}\text { Age, } \\
\mathbf{y}\end{array}$} & \multirow[b]{2}{*}{ Comorbidity } & \multirow{2}{*}{$\begin{array}{l}\text { AoVArea } \\
\mathrm{cm}^{2}\end{array}$} & \multirow{2}{*}{$\begin{array}{l}\text { MAoG } \\
\text { mm Hg }\end{array}$} & \multirow{2}{*}{$\begin{array}{l}\text { Peak Ao } \\
\Delta \mathrm{mm} \mathrm{Hg}\end{array}$} & \multirow[b]{2}{*}{ LVEF $\%$} & \multicolumn{2}{|c|}{ EuroSCORE } & \multicolumn{2}{|c|}{ Society of Thoracic Surgeons } \\
\hline & & & & & & & & Additive & Logistic & Mortality & Morbidity \\
\hline 1 & M & 78 & $\begin{array}{l}\text { Vasculopathy, porcelain aorta, } \\
\text { previous PCI }\end{array}$ & 0.8 & 51 & 90 & 69 & 8 & 10 & $6.3 \%$ & $28.9 \%$ \\
\hline 2 & $\mathrm{~F}$ & 85 & $\begin{array}{l}\text { Vasculopathy, } \\
\text { thrombocythemia }\end{array}$ & 0.8 & 51 & 93 & 67 & 11 & 20 & $8.7 \%$ & $29.9 \%$ \\
\hline 3 & M & 74 & $\begin{array}{l}\text { Vasculopathy, AMI, bladder } \\
\text { neoplasm, IDDM, previous } \\
\text { CABG and PCI }\end{array}$ & 1 & 52 & 81 & 58 & 12 & 27 & $11 \%$ & $41.9 \%$ \\
\hline 4 & M & 86 & $\begin{array}{l}\text { Vasculopathy; IDDM, CRI, } \\
\text { previous PCI }\end{array}$ & 0.9 & 47 & 80 & 30 & 15 & 53 & $14.6 \%$ & $42.7 \%$ \\
\hline 5 & M & 85 & Vasculopathy, stroke & 0.9 & 62 & 104 & 49 & 13 & 39 & $5.2 \%$ & $30 \%$ \\
\hline 6 & M & 85 & Vasculopathy, IDDM, AMI, & 1.1 & 47 & 82 & 26 & 16 & 59 & $13.7 \%$ & $45.5 \%$ \\
\hline
\end{tabular}

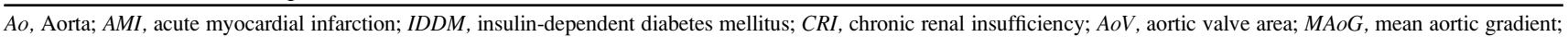
Peak Ao $\triangle \mathrm{mm} \mathrm{Hg}$, echo peak transvalvular aortic pressure gradient; $L V E F$, left ventricular ejection fraction; $P C I$, percutaneous coronary intervention; $C A B G$, coronary artery bypass grafting. 


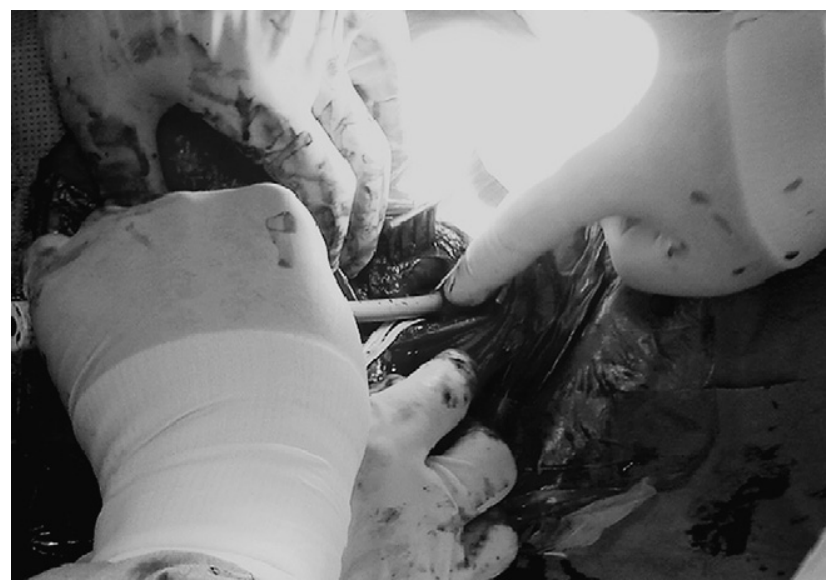

FIGURE 1. After subclavian exposure, the $18 \mathrm{~F}$ introducer is inserted over an Amplatz (Amplatz Cook, Inc, Bloomington, Ind) super stiff guidewire.

CoreValve in the aortic root. Good valve performance was evidenced by a reduction in mean transaortic gradient to less than $20 \mathrm{~mm} \mathrm{Hg}$ and aortic regurgitation grade of 2 or less, as evaluated by aortic angiogram or echocardiogram. Operative outcome was represented by any event occurring during the procedure and within the subsequent 24 hours. Any events occurring within 30 days from the procedure were considered procedure related. ${ }^{12}$ Events collected were death, neurologic event, myocardial infarction, ventricular perforation, cardiac tamponade, aortic dissection, vascular access complication, infections, and contrast-induced

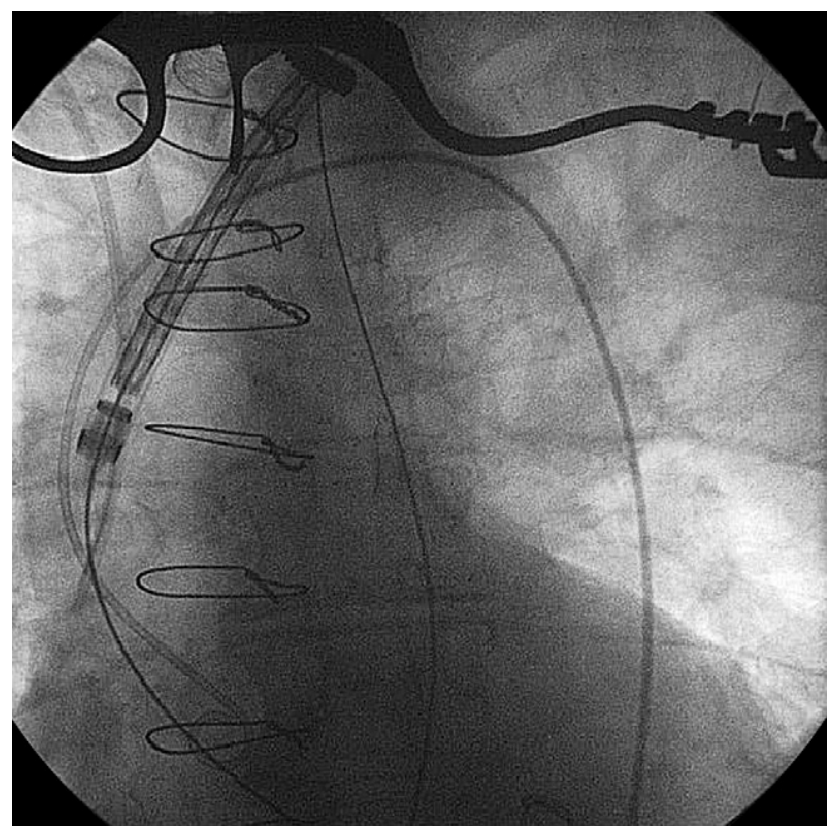

FIGURE 2. CoreValve (Medtronic CV Luxembourg S.a.r.1.) delivery catheter and prosthesis are advanced in place. Notice the short distance from the subclavian access to the aortic annulus requiring weaker forces of tension and torsion.

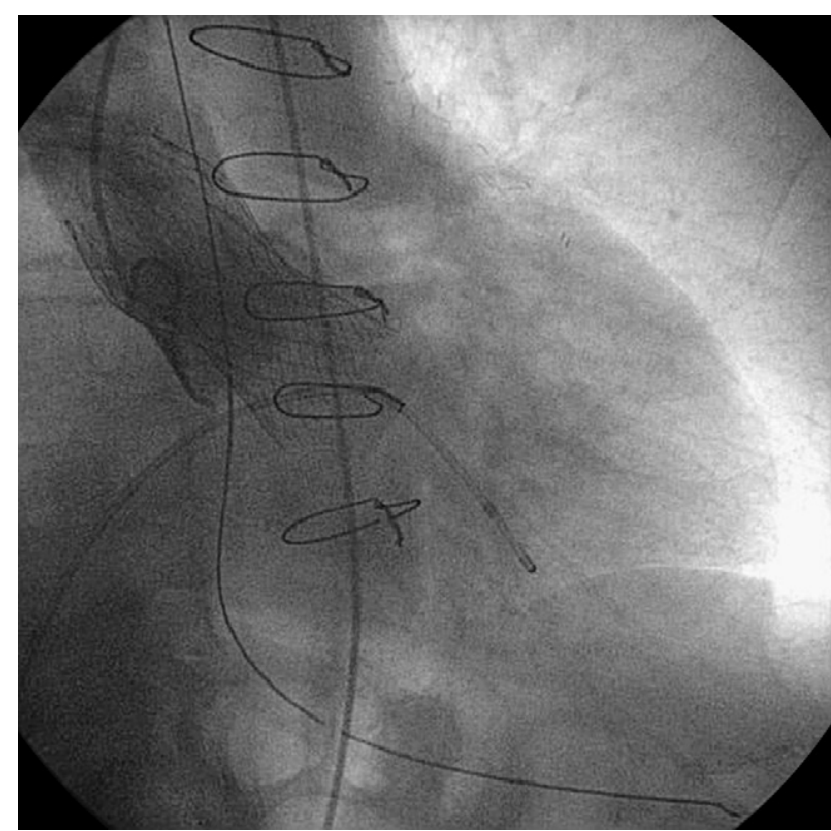

FIGURE 3. Immediately after CoreValve deployment, ascending aorta angiography was performed to assess the correct positioning of the device, periprosthesis regurgitation, and patency of the coronary arteries.

nephropathy. The CoreValve was inserted through the left subclavian artery in 6 patients. In patient 6 , the procedure was performed through the left subclavian artery with a patent left internal thoracic artery graft on the descending anterior coronary artery. Aortic valvuloplasty was performed to predilate the native valve in all patients. The mean duration of the procedure was $147 \pm 63$ minutes (range, 105-270 minutes), with a mean fluoroscopy time of $28 \pm 14$ minutes and a mean contrast medium amount of $186 \pm 84 \mathrm{~mL}$. Procedural success was obtained in all cases. Mean aortic gradient decreased $5 \mathrm{~mm} \mathrm{Hg}$ or less immediately after valve deployment in all patients. Two patients had grade 1 to 2 aortic insufficiency (Table 2). In patient 6, post-deployment valve dilation was performed to improve CoreValve strut expansion to reduce paraprosthetic leak. After removal of the $18 \mathrm{~F}$ sheath and surgical closure of the axillary artery, the radial pulse disappeared in patient 4 . The surgeon had also some difficulty in obtaining an adequate hemostasis at the puncture site. An immediate angiography at this level revealed a long dissection with a flow-limiting stenosis at the puncture site, which was treated with Gore Viabahn $8 \times 50$ $\mathrm{mm}$ (WL Gore and Associates Inc, Flagstaff, Ariz) covered polytetrafluoroethylene stent implantation. At 8 months follow-up, the left radial pulse is normal in this patient. All patients were extubated after the end of the procedure in the catheterization laboratory. Post-implant complete atrioventricular block developed in patient 5 , who required permanent pacemaker implantation via the right subclavian vein. All patients were asymptomatic on discharge with 
TABLE 2. Procedural details and complications

\begin{tabular}{ccccccc}
\hline Patient & Valve size (mm) & Implant time (min) & ${\text { DAP } \mathbf{G y c m}^{\mathbf{2}}}$ & P-t-P Ao gradient $(\mathbf{m m} \mathbf{H g})$ & Aortic insufficiency & Complications \\
\hline 1 & 29 & 110 & 213 & 4 & $1+$ & $1+$ \\
2 & 26 & 105 & 50 & 5 & $1+$ & - \\
3 & 29 & 115 & 105 & 5 & $1+$ & Subclavian stent \\
4 & 29 & 270 & 240 & 2 & $1-2+$ & PM implant \\
5 & 29 & 160 & 313 & 4 & $1-2+$ & ARF \\
6 & 29 & 125 & 212 & 4 & \\
\hline
\end{tabular}

$D A P$, Radiation dose/area product; $P$ - $t-P$ Ao, hemodynamic peak-to-peak trans-aortic gradient; $P M$, pacemaker; $A R F$, acute renal failure (creatinine clearance $<30 \mathrm{~mL} / \mathrm{min}$ ).

good prosthesis function as assessed by echocardiography after a mean hospitalization of 13 days (range 7-22 days) with a dual antiplatelet regimen of aspirin $100 \mathrm{mg}$ and clopidogrel $75 \mathrm{mg}$ daily for 3 months, after which $100 \mathrm{mg}$ of aspirin daily was prescribed indefinitely. Regular clinical and echocardiography follow-up were performed after discharge in all patients at 1, 3, 6, and 12 months and if clinically necessary. At discharge the average of mean transvalvular aortic pressure gradient was $9 \pm 4 \mathrm{~mm} \mathrm{Hg}$. During follow-up, all patients experienced functional class improvement after CoreValve implant at a mean time of $341 \pm 166$ days (range 41-470 days). Five patients are asymptomatic and have returned to normal life activities, limited only by their previous medical conditions. One patient was rehospitalized after discharge and died of pneumonia 41 days after the procedure. Two patients required femoral artery percutaneous transluminal angioplasty, and 1 patient underwent iliac-femoral bypass surgery. One patient experienced lower-extremity cholesterinic embolism that was successfully medically treated (Table E1). Echocardiographic controls, at 1 year, showed stable and good prosthesis performance, with an average mean transvalvular aortic pressure gradient of $9 \pm 4 \mathrm{~mm} \mathrm{Hg}$, and mild aortic insufficiency caused by trivial paravalvular leak in 3 patients (Table E2).

\section{DISCUSSION}

TAVI has emerged as an alternative therapy to treat patients with symptomatic AS who are not considered for surgery because of high-risk surgical features. ${ }^{7,8}$ In the last 5 years, approximately 10,000 patients have been treated worldwide for severe AS using a TAVI technique. ${ }^{13}$ Several technical approaches were applied, including antegrade approaches via the femoral vein and transseptal puncture, retrograde approaches via the femoral arteries, and the transapical approach via a minithoracotomy. ${ }^{4-6}$ The choice for the best approach depends on a patient's morbidity and tortuosity; the presence of excessive femoral, iliac, or aortic atherosclerosis; and the size and type of the device used.

The antegrade transvenous approach ${ }^{14}$ theoretically seems more suitable to introduce the large delivery system, reducing the risk of vascular complications. However, transseptal puncture makes this approach challenging, and passage of large-diameter catheters through the mitral valve may damage the mitral valve apparatus; thus, this approach has been abandoned. ${ }^{5}$

After reducing the size of the delivery catheters, the preferred access site for TAVI is the retrograde approach via the femoral arteries; however, actual selection criteria of patients of advanced age with porcelain aorta or previous cardiac surgery, select a cohort of patients at high risk for peripheral artery disease, and non-permissive retrograde transfemoral arterial approach. This condition may be overcome by a transapical approach widely and successfully performed using the Edwards-Sapien valve. ${ }^{6,15}$ This approach allows the introduction of delivery systems directly through the apex of the left ventricle without sheath diameter limitation. This approach is more invasive and requires an anterolateral minithoracotomy in a hybrid operating room. ${ }^{15}$ Moreover, transapical valve implantation has some technical limitations, as in the case of severe septal hypertrophy in combination with the angled position of the left ventricular outflow tract in relation to the aortic root and unique potential complications, such as significant incidence of perivalvular leak, myocardial perforation, and mitral or aortic trauma that may occur from misdirected stiff catheters. ${ }^{16,17}$ In this scenario, as recently reported by other authors, a trans-subclavian retrograde approach could represent an intriguing alternative for TAVI in high-risk patients with associated severe iliac-femoral arteriopathy. ${ }^{18-20}$ The axillary artery is easily accessible after surgical cutdown, and its size allows the introduction of $18 \mathrm{~F}$ sheaths. The CoreValve Extended Evaluation Registry has reported data for approximately 74 patients in whom subclavian access was used with $100 \%$ procedural success. ${ }^{21}$ Our experience confirms the possibility of performing CoreValve implantation through the left subclavian artery in a patient with a patent internal thoracic graft to the left anterior descending artery. In this case, as suggested by Fraccaro and colleagues, ${ }^{19}$ it may be safer to completely introduce the sheath only to implant the valve and then slightly retrieve the sheath to minimize the risk of thoracic flow obstruction. Some operators have experience with right subclavian access. ${ }^{18}$ This access is feasible even if correct positioning of the valve is made difficult by the fact that the stiff wire used to deliver the valve is pushed against the left aspect of the aorta. In case of aortic annuli with a significant inclination on the sagittal plane $(>30$ degrees; Jean-Claude Laborde, personal communication, March 2009), correct CoreValve implantation is difficult 
because of the difference in height of the 2 opposite parts of the annulus. In the trans-subclavian approach, the proximity between the aortic annulus and the sheath of the valve provides more direct access to the implantation site, easier manipulation of the device, and correct positioning of the CoreValve (particularly during the stepwise retraction of the outer sheath that allows deployment of the self-expanding prosthesis) than the transfemoral approach, because no bending of the aorta and pelvic arteries hinders the control of the device.

The axillary approach also has the advantage of overcoming challenging aorto-ileo-femoral vascular disease, without the invasiveness of the transapical technique, and avoids the risk of dislodging atherosclerotic plaque during valve passage through the aorta, which may cause particulate embolization and subsequent stroke. None of our patients had neurologic events. As with the transapical approach, procedural times are longer than in percutaneous transfemoral implantation. ${ }^{15,19}$ In our experience, the subclavian procedural length (mean implant time 147 minutes) was longer than the percutaneous transfemoral implantation (mean implant time 111 minutes), but was comparable to the time necessary for an implant requiring femoral artery surgical cut-down, although the trans-subclavian approach enables a more rapid mobilization of the patients. Except for subclavian dissection in 1 patient, no other vascular problem occurred in our series; no other patients experienced bleeding or difficult surgical hemostasis despite double-antiplatelet therapy.

No surgical wound infections occurred, and all patients were discharged in good health conditions and stable hemodynamic compensation 2 weeks after valve implant. During follow-up, all patients had improved New York Heart Association functional class and functional capacity, and echocardiograms showed good valve performance at 16 months.

In our series, 2 patients required permanent pacemaker implantation after TAVI. Permanent pacemaker requirement after CoreValve implantation is reported to be $33 \%$ inhospital and $40 \%$ within 1 year. The cause is that the native aortic valve remains in situ and is compressed by the CoreValve stent frame against the surrounding structures adjacent to the left ventricular outflow and aortic annulus, including the atrioventricular node and its left bundle branch. ${ }^{22}$

\section{CONCLUSIONS}

Our experience, characterized by a multidisciplinary contribution necessary to offer the safest conditions and care for patients, confirms the safety and feasibility of the subclavian approach with the immediate hemodynamic success of the treatment.

\section{References}

1. Lindroos M, Kupari M, Heikkila J, Tilvis R. Prevalence of aortic valve abnormalities in the elderly: an echocardiographic study of a random population sample. J Am Coll Cardiol. 1993;2:1220-5.

2. Bonow RO, Carabello B, Chatterjee K, et al. ACC/AHA 2006 guidelines for the management of valvular heart disease. J Am Coll Cardiol. 2006;48:e1-148.

3. Charlson E, Legedza AT, Hamel MB. Decision-making and outcomes in severe symptomatic aortic stenosis. J Heart Valve Dis. 2006;15:312-21.

4. Cribier A, Eltchaninoff $\mathrm{H}, \mathrm{Bash} \mathrm{A}$, et al. Percutaneous transcatheter implantation of an aortic valve prosthesis for calcific aortic stenosis: first human case description. Circulation. 2002;106:3006-8.

5. Webb JG, Chandavimol M, Thompson C, et al. Percutaneous aortic valve implantation retrograde from the femoral artery. Circulation. 2006;113:842-50.

6. Ye J, Cheung A, Lichtenstein SV, et al. Transapical aortic valve implantation in humans. J Thorac Cardiovasc Surg. 2006;131:1194-6.

7. Grube E, Buellesfeld L, Mueller R, et al. Progress and current status of percutaneous aortic valve replacement: results of three device generations of the CoreValve Revalving System. Circ Cardiovasc Intervent. 2008;1:167-75.

8. Webb JG, Altwegg L, Boone RH, et al. Transcatheter aortic valve implantationimpact on clinical and valve-related outcomes. Circulation. 2009;119:3009-16.

9. Grube E, Laborde JC, Gerckens U, et al. Percutaneous implantation of the CoreValve self-expanding valve prosthesis in high-risk patients with aortic valve disease: The Siegburg First-in-Man Study. Circulation. 2006;114:1616-24.

10. Leon MB, Kodali S, Williams M, et al. Transcatheter aortic valve replacement in patients with critical aortic stenosis: rationale, device descriptions, early clinical experiences, and perspectives. Semin Thorac Cardiovasc Surg. 2006;18: 165-74.

11. Marcheix B, Lamarche Y, Berry C, et al. Surgical aspects of endovascular retrograde implantation of the aortic CoreValve bioprosthesis in high-risk older patients with severe symptomatic aortic stenosis. J Thorac Cardiovasc Surg. 2007; 134:1150-6.

12. Piazza N, Grube E, Gerckens U, et al. Procedural and 30-day outcomes following transcatheter aortic valve implantation using the third generation (18 Fr) CoreValve ReValving System: results from the multicentre, expanded evaluation registry 1-year following CE mark approval. EuroIntervention. 2008;4:242-9.

13. PC Block: The Next Generation of Transcatheter Aortic Valve Devices. Cardiac Interventions Today. 2009: September 79-82. Available at: http://www.bmctoday.net/ citoday/2009/09. Accessed September 20, 2009.

14. Cribier A, Eltchaninoff H, Tron C, et al. Early experience with percutaneous transcatheter implantation of heart valve prosthesis for the treatment of end-stage inoperable patients with calcific aortic stenosis. J Am Coll Cardiol. 2004;43:698-703.

15. Walther T, Simon P, Dewey T, et al. Transapical minimally invasive aortic valve implantation multicenter experience. Circulation. 2007;116(11 Suppl):I240-5.

16. Lichtenstein SV, Cheung A, Ye J, et al. Transapical transcatheter aortic valve implantation in humans: initial clinical experience. Circulation. 2006;114:591-6.

17. Ye J, Cheung A, Lichtenstein SV, et al. Transapical transcatheter aortic valve implantation: 1-year outcome in 26 patients. J Thorac Cardiovasc Surg. 2009;137: 167-73.

18. Ruge H, Lange R, Bleiziffer S, et al. First successful aortic valve implantation with the CoreValve ReValving System via right subclavian artery access: a case report. Heart Surg Forum. 2008;11:E323-4

19. Fraccaro C, Napodano M, Tarantini G, et al. Expanding the eligibility for transcatheter aortic valve implantation: the trans-subclavian retrograde approach using the III Generation CoreValve Revalving System. J Am Coll Cardiol Interv. 2009; 2:828-33.

20. Jilaihawi H, Spyt T, Chin D, Logtens E, Laborde JC, Kovac J. Percutaneous aortic valve replacement in patients with challenging aortoiliofemoral access. Catheter Cardiovasc Interv. 2008; 72:885-90.

21. Medtronic's CoreValve shows subclavian access success in patients contraindicated for femoral approach [press release]. Available at: http://www.medicalnewstoday. com/articles/150929.php. Accessed July 23, 2009.

22. Jilaihawi H, Chin D, Vasa-Nicotera M, et al. Predictors for permanent pacemaker requirement after transcatheter aortic valve implantation with the CoreValve bioprosthesis. Am Heart J. 2009;157:860-6. 


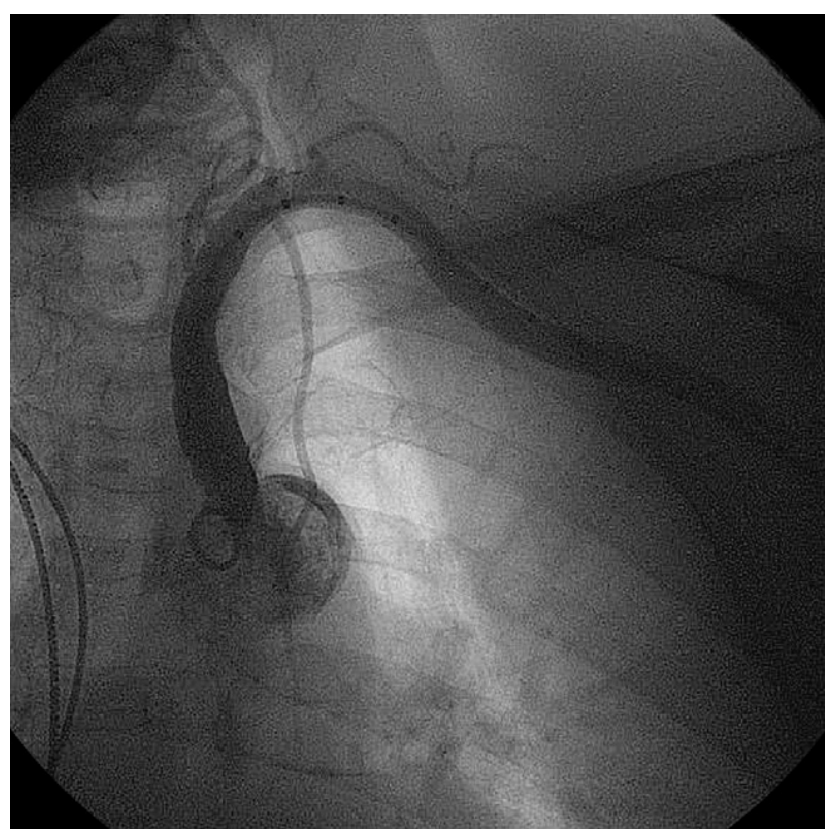

FIGURE E1. Supra -aortic vessel angiography to assess left subclavian artery size, course, and calcification.

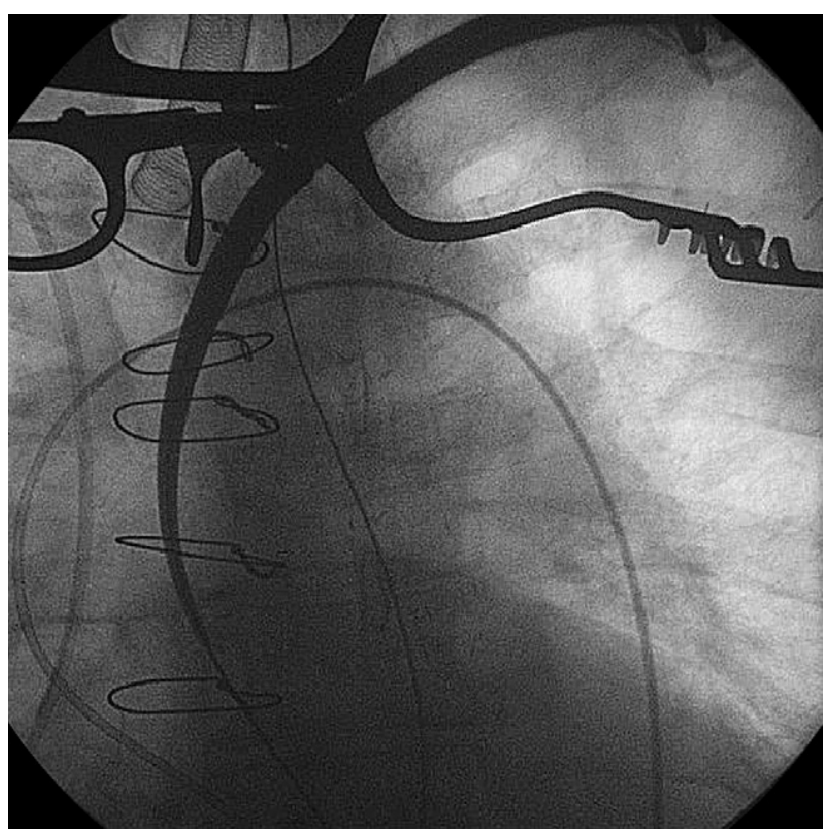

FIGURE E3. The CoreValve revalving system $18 \mathrm{~F}$ introducer was carefully advanced to the ascending aorta.

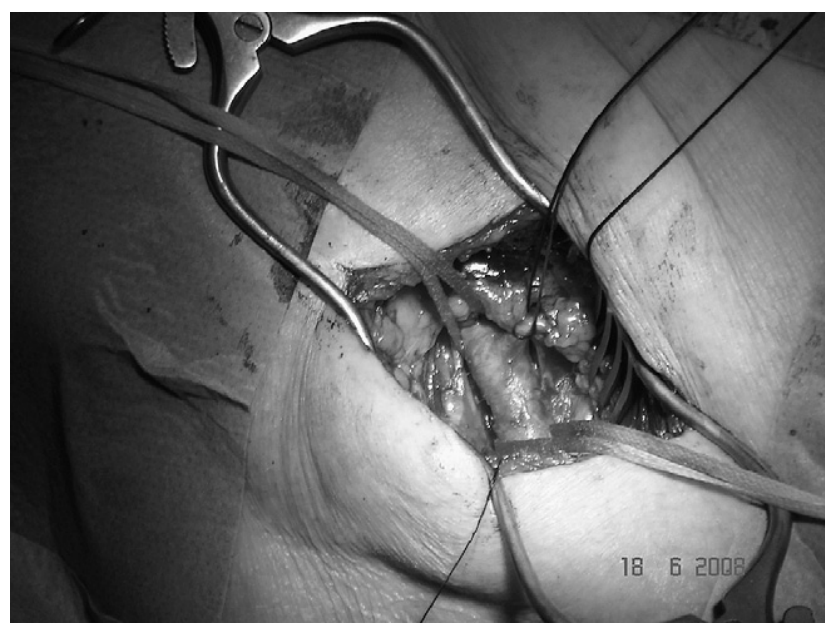

FIGURE E2. Subclavian exposure after incision of cutaneous and subcutaneous tissue.

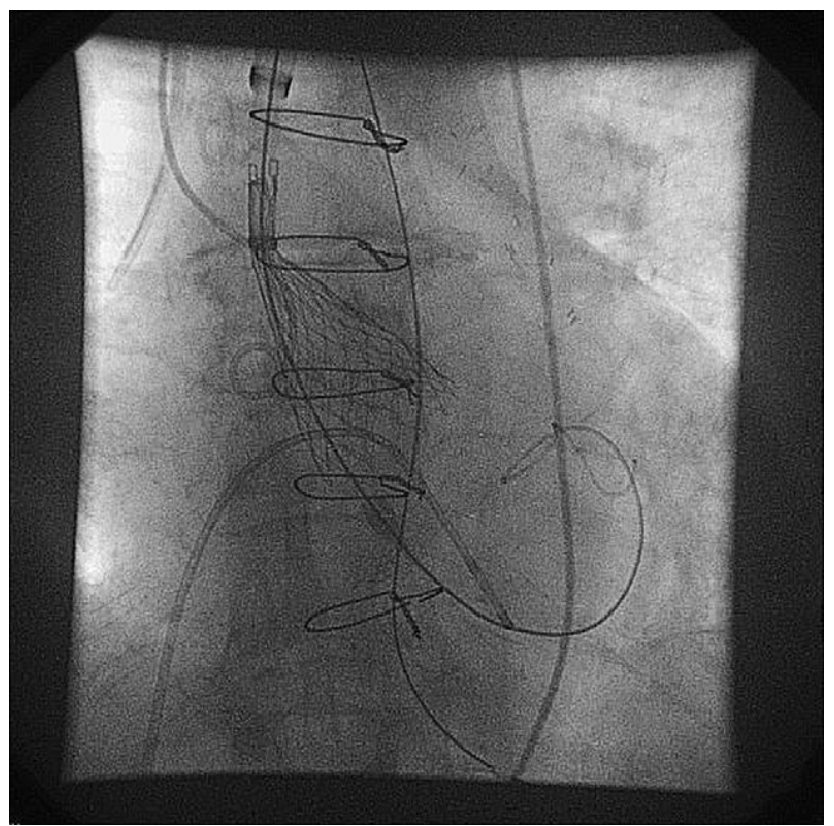

FIGURE E4. After careful checking of the CoreValve's position, the valve was released. 
TABLE E1. Patients' clinical follow-up

\begin{tabular}{ccllc}
\hline Patient & $\begin{array}{c}\text { NYHA } \\
\text { class }\end{array}$ & \multicolumn{1}{c}{ Events } & Outcome & $\begin{array}{c}\text { Follow-up } \\
\text { (mo) }\end{array}$ \\
\hline 1 & I & AF, PM & Alive & 16 \\
2 & I & $\begin{array}{c}\text { PTA and iliac-femoral } \\
\text { bypass of femoral artery }\end{array}$ & Alive & 15 \\
& & Alive & 15 \\
3 & I & PTA of femoral artery & Alive & 12 \\
4 & II & HF episode & Death & 1 \\
5 & NA & Pneumonia & Alive & 9 \\
6 & I & Cholesterinic embolism &
\end{tabular}

NYHA, New York Heart Association; $A F$, atrial fibrillation; $P M$, pacemaker; $P T A$, percutaneous transluminal angioplasty; $H F$, heart failure.

TABLE E2. Patients' echocardiographic follow-up

\begin{tabular}{|c|c|c|c|c|c|c|c|c|c|}
\hline \multirow[b]{2}{*}{ Patient } & \multicolumn{3}{|c|}{$1 \mathrm{mo}$} & \multicolumn{3}{|c|}{$6 \mathrm{mo}$} & \multicolumn{3}{|c|}{$1 y$} \\
\hline & MAoG mm Hg & LVEF \% & AoI & MAoG mm Hg & LVEF \% & AoI & MAoG mm Hg & LVEF \% & AoI \\
\hline 1 & 10 & 63 & $1+$ & 6 & 50 & $1+$ & 8 & 50 & $1+$ \\
\hline 2 & 6 & 65 & 0 & 6 & 51 & 0 & 13 & 54 & 0 \\
\hline 3 & 9 & 58 & $1+$ & 11 & 63 & $1+$ & 9 & 64 & $1+$ \\
\hline 4 & 4 & 35 & $1+$ & 5 & 37 & $1+$ & 4 & 38 & $1+$ \\
\hline 5 & 16 & 50 & 2 & - & - & - & - & - & - \\
\hline 6 & 11 & 49 & $1-2+$ & 6 & 53 & - & - & - & - \\
\hline
\end{tabular}

$M A o G$, Mean aortic gradient; $A o I$, aortic insufficiency; $L V E F$, left ventricular ejection fraction. 